\title{
The Organizational Design of Offshoring
}

\author{
Marcus M. Larsen \\ Ph.D. awarded by Copenhagen Business School, Denmark, April 2013
}

\section{Introduction}

Why do some firms fail when offshoring and others do not? In an age where the relocation of business activities abroad is common practice, this is an important - yet largely ignored - question with central implications for both research and practice. Through a collection of four research papers, this dissertation suggests that offshoring initiates a more fundamental reconfiguration process that essentially challenges firms' capacity to manage the complexities of operating an international organization. Firms tend to ignore the coordinative challenges of altering an organization from being primarily co-located to becoming highly international. Consequently, firms are caught up by what has been called the "harsh realities of offshoring" (Aron and Singh, 2005: 135).

Offshoring can be defined as the relocation of organizational tasks and services to foreign locations in internal, cooperative or outsourced arrangements (Lewin et al., 2009). Driven by objectives such as cost reduction, market proximity and access to strategic resources, the scale and scope of offshoring reached unprecedented levels with firms relocating tasks and activities from the entire value chain. Increasingly, however, many firms have begun to realize that managing an increasingly globally dispersed organization is more difficult and costly than initially expected. The business press is rich with examples of firms that are beginning to back-source or re-nationalize their offshored activities. In particular, it seems that decision makers often fail to accurately estimate the costs and benefits of offshoring and are therefore surprised by unexpected challenges of implementing offshoring decisions (e.g., Stringfellow et al., 2008).

To understand why firms fail when relocating activities abroad, I focus in this dissertation on the organizational design of offshoring. Specifically, I follow a tradition that views firms as systems of complex interdependent activities that must be coordinated to optimize organizational performance (Thompson, 1967; Siggelkow, 2001). For example, since organizational activities require ongoing interaction to coordinate decisions and behaviors, a growing number of interdependencies increases the number of channels to coordinate joint and interdependent organizational actions (Thompson, 1967). This, in turn, affects the organizational ability to process information (Simon, 1955) and increases the risk of organizational inefficiencies, inertia and decision errors (Levinthal, 1997).
This interdependency view is particularly salient within the context of offshoring. For example, how does the added distance between the organizational activities signified by offshoring impact task interdependencies and performance? How do bounded rational decision makers account for and plan the organizational change from co-location to international dispersion? How do firms accumulate architectural knowledge so that efficient design decisions can be taken when relocating certain activities to foreign locations?

When activities are geographically co-located and day-to-day problems and challenges can easily be solved in an informal face-toface manner, firms may tend not to see the rationale of formalizing organizational mechanisms for coordination and knowledge transfer through standardized interfaces and clear divisions of labor. However, as offshoring signifies the relocation of originally co-located activities to foreign locations, operational efficiency may be hampered due to lack of trust, status differences between domestic and foreign units, and lack of understanding and communication in the process of delivering tasks, and interacting with offshore units. Employees with cultural and language differences at geographically dispersed locations are

\section{(S) Firms engaged in offshoring must implement coordination mechanisms that accommodate for the added distance between interdependent activities.}

refrained from informal face-to-face coordination, and are forced to rely on less superior technology-based coordination mechanisms. Opportunities for informal coordination are reduced and project teams may find it more difficult to build collegial social environments and common ground due to less communication and shared context.

Consequently, firms engaged in offshoring must implement coordination mechanisms that accommodate for the added distance between interdependent activities. The dispersion of organizational activities challenges bounded rational decision makers' ability to understand the true interdependency structure underlying various design efforts (cf., Simon, 1955). According to Thompson (1967: 13), "the central problem for complex organizations is one of coping with uncertainty." Firms need to design their organizations so that interdependent work is coordinated and supportive of organizational goals. As such, firms need 
to ensure that aspects such as knowledge transfer, coordination, and control are not obscured by the geographic, political and institutional distances between the onsite organization and offshoring activities.

\section{Summary of Research Papers}

The dissertation consists of four research papers that investigate different aspects of the organizational process of relocating firm activities to locations outside the home country. The first paper (Larsen et al., 2013) uses the context of services offshoring to investigate estimation errors due to hidden costs - the costs of implementation that are neglected in strategic decision-making processes. Based on data from the Offshoring Research Network, we argue that decision makers are more likely to make cost-estimation errors given increasing configuration and task complexity in captive offshoring and offshore outsourcing, respectively. Moreover, we show that experience and a strong orientation toward organizational design in the offshoring strategy reduce the costestimation errors that follow from complexity. The findings contribute to research on the effectiveness of sourcing and global strategies by stressing the importance of organizational design and experience in dealing with increasing complexity.

The second study builds on the first paper and investigates the performance consequences of the situations where decision makers' estimations of the costs of implementing offshoring decisions are surpassed by actual cost levels. Using unique data from the Global Operations Network - a research network of different Scandinavian universities studies industries and companies that been intensively exposed to globalization, and specifically how firms manage and coordinate their offshoring activities - I argue that cost estimation errors of implementing an activity in a foreign location have a negative impact on the process performance of that activity as operations are likely to be disrupted by managerial distraction and resource misallocation. Interestingly, however, I also find that this relationship is mitigated by the extent to which modularity is used as a coordination mechanism but made worse by the extent to which ongoing communication is used. This indicates that cost estimation errors should be regarded as a local problem that needs local accommodation, as the extent to which coordination with other geographically distant units is required induces politics and conflict of interests instead of attention to the offshored activity. Thus, the paper contributes to research on offshoring and strategic decision making by emphasizing the importance of organizational design and of estimating the costs of internal organizational change.

The purpose of the third paper (Larsen \& Pedersen, 2014) is to investigate the effect of the organizational reconfiguration of offshoring on firms'strategies. A consequence of offshoring is the need to reintegrate the geographically relocated organizational activities into a coherent organizational architecture. In order to do this, firms need a high degree of architectural knowledge which is typically gained through learning by doing. We therefore argue that firms with more offshoring experience are more likely to include organizational objectives in their offshoring strategies. This idea is developed using a mixed-method approach based on a qualitative case study of an R\&D subsidiary in the Nokia Corporation and comprehensive data from the Offshoring Research Network. The findings contribute to research on the organizational design and architecture of offshoring and the dynamics of organizational architectures.

Finally, the fourth paper builds an agent-based simulation model that examines the performance implications of how firms adapt when offshoring. Building on the argument that firms must accumulate architectural knowledge for efficient adaptation, we argue that offshoring firms face two basic strategies: a proactive learning strategy (homebased learning before the offshoring implementation) or a reactive learning strategy (learning-by-doing after the offshoring implementation). Our analyses suggest that the relative attractiveness of the reactive strategy decreases with distance and coordination costs but increases with uncertainty. Moreover, uncertainty has a positive moderating effect on the relationship between distance and the reactive strategy. Accordingly, by formalizing two different architectural knowledge strategies in the context of offshoring, the paper shows how important contingencies can lead to significant performance tradeoffs in the identification of optimal organizational configurations when internationalizing

\section{Implications for Practice and Research}

Taken together, the four papers suggest that the disintegration and relocation of organizational activities create complexity which, in turn, negatively impacts decision makers' ability to accurately estimate the costs caused by the organizational change from co-location to international dispersion (Paper 1). While this has negative performance implications for the offshored activity (Paper 2), factors such as organizational design orientation, modularity and international experience reduce this negative impact. In particular, firms' level of architectural knowledge is important in terms of anticipating and aligning offshoring complexity with corresponding organizational structures and processes. In this respect, firms can either accumulate knowledge reactively through learning-by-doing (Paper 3) or proactively through homebased learning (Paper 4). Thus, in order to understand why some firms fail when offshoring and others do not, these papers emphasize that the organizational consequences of relocating organizational activities to foreign locations entail complexities that require firms to invest additional resources in coordination so that efficient re- integration can be achieved.

These results have important contributions for business practice and future research. Seeing offshoring as an organizational reconfiguration highlights the importance of acknowledging and incorporating to a larger extent the organizational sphere in the analysis and practice of offshoring and multination corporations. By solely focusing on extracting location-specific advantages, firms are more likely to encounter severe challenges of managing an increasingly globally dispersed 
organization that eventually may cause failure. Rather, the argument put forth here is that firms need to manage the organizational complexities of offshoring to most effectively reap the benefits of foreign factor endowments such as low-cost labor and market access.

Further, the idea of hidden costs is new and has predominantly been treated anecdotally to underscore how offshoring might be more challenging than initially expected. This dissertation shows how multinational complexity drives cost estimation errors, shows how hidden costs deter process performance and identifies how firms' may manage hidden costs through strategy orientation, experience and modularity. These findings are important for both practice and research. On the one side, firms may benefit from these insights by thinking more strategically on how to approach offshoring: How can we assess the complexity of our future multinational organization? Which channels of communication will be disrupted by relocation of certain tasks? Are there ways we can economize on mechanisms of coordination? On the other side, these insights contribute to research that focuses on appropriate organizational designs in complex environments (Ethiraj \& Levinthal, 2004) and its inhibiting role on decision-making processes and decision makers' estimation ability (Durand, 2003). Further, this dissertation contributes to research focusing on the role and strategies of architectural knowledge in organizational change (Henderson \& Clark, 1990). Since offshoring signifies a change in the organizational configuration, it is demonstrated how firms need architectural knowledge on how the interdependencies spanning across geographies, cultures and institutions impact the organizational system and performance.

In conclusion, much research has argued that offshoring requires new theories to explain the phenomenon as the practice breaks with established theories on international expansion. In this thesis, offshoring is rather regarded as a unique empirical context in which existing theories on international expansion and organizational design can be investigated, extended and modified. The inherent challenges in changing a co-located organization to an internationally dispersed organization make offshoring an important empirical field for investigating complexity and design in contemporary organizations. Thus, offshoring should not be dealt with in isolation, but rather be viewed as a phenomenon that can further more established theoretical fields and practice of international business, strategic management and organizational design.

\section{References}

Aron, R., \& Singh, J. V. 2005. Getting offshoring right. Harvard Business Review, 83(12): 135-143.

Durand, R. 2003. Predicting a firm's forecasting ability: The roles of organizational illusion of control and organizational attention. Strategic Management Journal, 24(9): 821-838.
Ethiraj, S. K., \& Levinthal, D. 2004. Bounded rationality and the search for organizational architecture: An evolutionary perspective on the design of organizations and their evolvability. Administrative Science Quarterly, 49(3): 404-437.

Henderson, R. M., \& Clark, K. B. 1990. Architectural innovation:The reconfiguration of existing product technologies and the failure of established firms. Administrative Science Quarterly, 35(1): 9-30.

Larsen, M. M., Pedersen, T. 2014. Organizational reconfiguration and strategic orientation: The case of offshoring. Advances in International Management, 27: 403-432.

Larsen, M. M., Manning, S., \& Pedersen, T. 2013. Uncovering the hidden costs of offshoring: The impact of complexity, design orientation and experience. Strategic Management Journal, 34(5): 533-552.

Levinthal, D. A. 1997. Adaptation on rugged landscapes. Management Science, 43(7): 934-950.

Lewin, A. Y., Massini, S., \& Peeters, C. 2009. Why are companies offshoring innovation? The emerging global race for talent. Journal of International Business Studies, 40 (8): 1406-1406.

Siggelkow, N. 2001. Evolution toward fit. Administrative Science Quarterly, 47(1): 125-159.

Simon, H. A. 1955. A behavioral model of rational choice. The Quarterly Journal of Economics, 69(1): 99-118.

Stringfellow, A., Teagarden, M. B., \& Nie, W. 2008. Invisible costs in offshoring services work. Journal of Operation Management, 26(2): 164-179.

Thompson, J. D. 1967. Organizations in action: Social science bases of administrative theory. New York: McGraw-Hill.

Marcus M. Larsen is an Assistant Professor at Department of Strategic Management and Globalization, Copenhagen Business School. His research focuses on the organizational design of multinational corporations and the rise of emerging economy multinationals. His research is published / forthcoming in journals such as the Strategic Management Journal, the Journal of International Business Studies, the Global Strategy Journal, and the Journal of International Management. He has also published a number of teaching cases. 